\title{
AIRBORNE LIDAR BATHYMETRY APPLIED TO COASTAL HYDRODYNAMIC PROCESSES
}

\author{
Bernard F. Long, Francis Aucoin, Stéphane Montreuil, Valérie Robitaille and Régis Xhardé ${ }^{1}$
}

\begin{abstract}
In this study, the possibility to get sedimentological (density, compaction) and hydrodynamical (suspended sediment concentration, turbulence) information from ALB surveys is demonstrated. ALB laser reflectance was found to be higher on the lee-side and on the crest of the ripple bedform than in the trough and on the stoss-side. Moreover, laser reflectance was also found to be higher on "active" subtidal dunes, located within the depth of action of the waves, than on deeper "passive" bedforms. Based on lab experiments conducted in a hydraulic flume under X-ray CT-Scanner, these observations were related to sediment compaction and suspended sediment.
\end{abstract}

Keywords: laser reflectance; hydrodynamics; bedform; ALB; CT-Scanner; hydraulic flume

\section{INTRODUCTION}

Airborne LiDAR bathymetry (ALB) has proven to be an efficient laser-based tool to monitor coastal environments and to map biological habitats (Collin et al. 2008, 2010) or geomorphology (Cottin et al. 2009, Xhardé et al., 2010). In this study, the possibility to get sedimentological (porosity, compaction) and hydrodynamical (suspended sediment concentration, turbulence) information from ALB surveys was investigated. To do that, ALB data were collected in 2006 over a test site and the laser return intensity waveforms were analyzed. Statistical parameters were extracted from the waveform and correlated to bedform morphology and water depth. Another experiment was conducted in laboratory to study sediment transport dynamics with a hydraulic flume under CT-Scanner. Tomographic X-ray intensity and laser reflectance measurements were acquired simultaneously on sand ripple bedforms. Field and laboratory laser reflectance were related to tomographic intensities, sediment density (i.e. compaction) and suspended sediment transport, demonstrating the capacity of ALB surveys to provide relevant information about hydrodynamic processes involved in subtidal bedform dynamics.

\section{STUDY AREA}

The present study focuses on the cuspate foreland of Paspebiac, located along the north shore of the Chaleurs Bay, in the western Gulf of Saint Lawrence, Canada (Fig. 1, left). This area is a fetchlimited low wave-energy site characterized by a significant wave height of $0.95 \mathrm{~m}$, a peak period of 4.1 $\mathrm{s}$ and extreme values of $3.38 \mathrm{~m}\left(\mathrm{H}_{\max }\right)$ and $10 \mathrm{~s}\left(\mathrm{~T}_{\max }\right)$ (Xhardé et al. 2010). The dominant wave directions are respectively to the west (27.7\% of the time), to the east (13.9\%) and to the northeast (11.6\%). Storm waves with $\mathrm{H}_{\mathrm{s}}$ exceeding $2 \mathrm{~m}$ are mainly originating from the northeast (Gulf of SaintLawrence) and from the southwest (Xhardé et al. 2010). The limit of wave action is approximately $5 \mathrm{~m}$ $\left(2 \mathrm{H}_{\mathrm{s}}\right)$ but wave-generated currents can reworked the seabed to depths of at least $14 \mathrm{~m}$ during major storm events (Cottin 2008, Xhardé 2010). Tides are meso-tidal (spring tide range $=2 \mathrm{~m}$ ) and tide currents don’t exceed 1 knot ( 50 cm/s) according to the Canadian Hydrographic Survey (2006).

The foreland of Paspebiac is formed of two transgressive mixed sand-gravel barriers of approximately $1.5 \mathrm{~km}$ long, delimiting a triangle-shaped tide-dominated salt marsh (Fig. 1, right). This foreland is the emerged part of a larger submarine sedimentary structure of approximately $3 \mathrm{~km}$ long and $1.2 \mathrm{~km}$ wide $\left(\sim 3.6 \mathrm{~km}^{2}\right)$ extending to a depth of $14 \mathrm{~m}$ (Fig. 1, right) forming the end of the local coastal sediment transport (Renaud 2000, Xhardé et al. 2010). East of the foreland, the offshore bathymetry exhibited semi-regular shore-oblique subtidal dunes which appeared to be part of a field of overlapping dunes covering an area of about $360000 \mathrm{~m}^{2}$ and were located at depths ranging from $5 \mathrm{~m}$ to 14 m (Cottin 2008, Xhardé et al. 2010).

\footnotetext{
${ }^{1}$ INRS-ETE, rue de la Couronne, Quebec, Quebec, G1K 9A9, Canada
} 


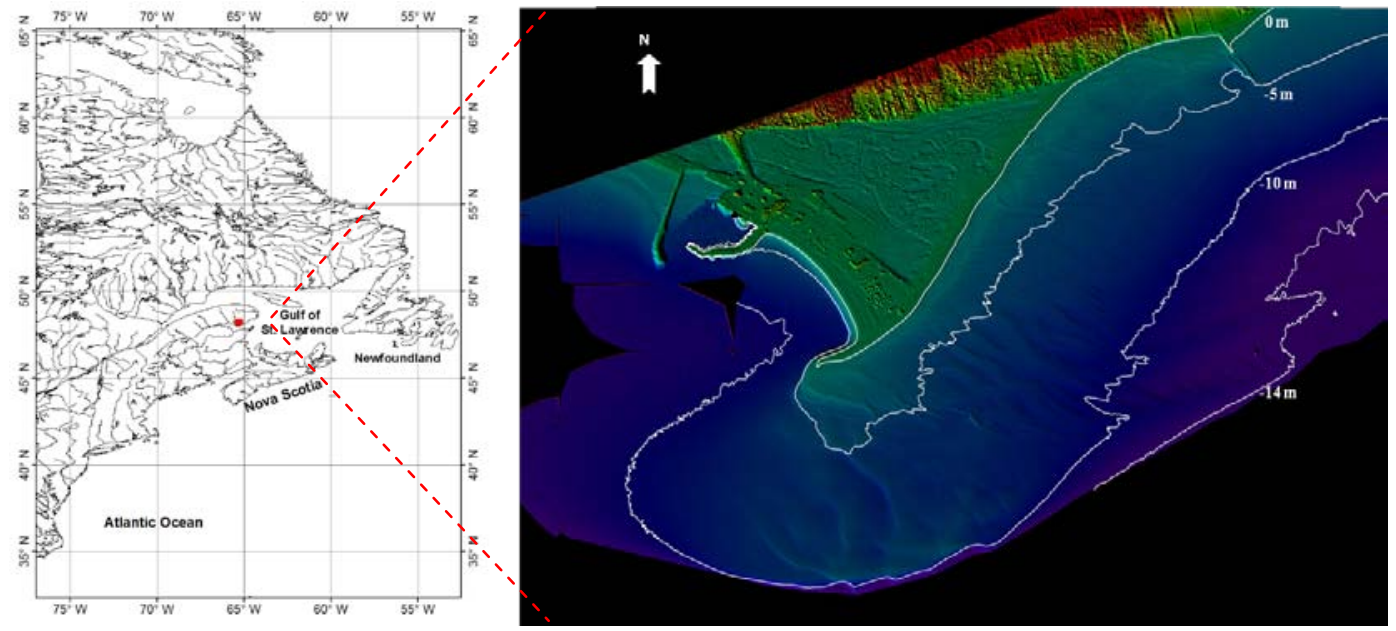

Figure 1. Paspébiac cuspate foreland, Quebec, Canada. A digital elevation model (DEM) of the topography and bathymetry on the site is shown on the right figure. Depths are referred to the mean sea level and expressed in meters.

Their main morphologic characteristics (amplitude $(\mathrm{H})$; crest-to-crest spacing or wavelength $(\lambda)$; orientation $\left({ }^{\circ}\right)$ and shape) allowed us to classify them into four main bedform morpho-types, following Ashley's subtidal bedform classification (1990):

- $\quad$ Very large asymmetric dunes $(1.5 \mathrm{~m}<\mathrm{H}<2 \mathrm{~m} ; \lambda \sim 125 \mathrm{~m})$

- $\quad$ Large asymmetric dunes $(0.5<\mathrm{H}<1 \mathrm{~m} ; \lambda \sim 70-80 \mathrm{~m})$

- $\quad$ Large symmetric or asymmetric dunes $(0.3<\mathrm{H}<0.5 \mathrm{~m} ; \lambda \sim 50-60 \mathrm{~m})$

- $\quad$ Medium symmetric or asymmetric dunes $(\mathrm{H}<0.3 \mathrm{~m} ; \lambda \sim 12-20 \mathrm{~m})$

Two dominant dune orientations were also observed: to the northeast and to the northwest. The former orientation characterized the shallower active dunes $(<-10 \mathrm{~m})$ while the latter was mainly observed on the very large asymmetric and inactive dunes, which were also the deepest ones $(>-10 \mathrm{~m})$. These subtidal dunes were interpreted as flow-transverse bedforms that develop under unidirectional wave- or tide-generated currents and their orientations were related to the two dominant storm wave directions (Cottin 2008, Xhardé et al. 2010).

\section{DATA AND METHODS}

\section{ALB Survey}

Airborne laser systems (or LiDAR) are laser-based scanning altimeters allowing the collect of highly accurate and spatially dense topographic (Airborne Laser Topographic Mapper) and/or bathymetric (Scanning Hydrographic and Oceanographic Airborne LiDAR Survey) data over regional scales (Krabill et al. 1995, Baltsavias 1999, Brock et al. 2002, Stockdon et al. 2002, Woolard and Colby 2002, Sallenger et al. 2003, Riley, 1995, Pope et al., 1997, Irish et al., 2000). These highly accurate mapping systems ensure full coverage of the coastal zone, from the backshore to depths of 2 or 3 Secchi depths (with hydrographic systems), and detailed studies of coastal and submarine environments (Riley 1995, Pope et al. 1997, Irish et al. 2000, Collin et al. 2008, Collin et al. 2010, Cottin et al. 2010).

For this study, a bathymetric survey was performed in July 2006 with a Scanning Hydrographic and Oceanographic Airborne LiDAR Survey (SHOALS) system from Optech Inc., operated by Dynamic Aviation and Optech Inc. This system is based on a monostatic dual-frequency laser emitting short laser pulses (6 ns) at $532 \mathrm{~nm}$ (green-blue) and $1064 \mathrm{~nm}$ (IR) wavelengths at a rate of 3,000 $\mathrm{Hz}$ (in hydrographic mode) or $10,000 \mathrm{~Hz}$ (in topographic IR mode). The former wavelength is typically used for seabed detection due to its high water penetration while the latter wavelength is used for sea surface detection and topographic data acquisition. The maximum water depths that can be detected by SHOALS depend mainly on water turbidity, which reduces light propagation through the water column by scattering and absorption (Irish et al., 2000). In this study, the maximum surveyed depth was -16.7 $\mathrm{m}$ and the mean ground sounding spacing was $4 \mathrm{~m}$ (Cottin 2008). Vertical precisions of both 
topographic and hydrographic data are estimated to $\pm 15 \mathrm{~cm}$ and horizontal accuracy varies from $\pm 1 \mathrm{~m}$ to \pm 4 m (Riley 1995, Pope et al. 1997, Irish et al. 2000).

In addition, the SHOALS system is able to record laser energy return time series (waveforms). This is achieved with four receivers: one records the infrared energy reflected from the water surface (surface return), two collect the green energy reflected from the sea bottom (one for shallow water (0.2-12 $\mathrm{m}$ ) and one for deep water $(\ell 7 \mathrm{~m})$ ), and the fourth receiver records Raman energy, at $645 \mathrm{~nm}$, which results from excitation of water molecules at the sea surface by the green laser energy (Raman 1928, Guenther et al. 2000). The infrared and Raman waveforms are used to localize the air/water interface while the green waveform is used to detect sea bottom. For each channel, the received signal is converted into a voltage, amplified (logarithmically) and digitized at $1 \mathrm{GHz}$ with 8 bits of resolution (256 levels). Assuming the celerity of light in physical elements, each bin, i.e. one nanosecond, corresponds to a vertical resolution of $0.15 \mathrm{~m}$ and $0.1125 \mathrm{~m}$ in air and water respectively (Collin et al. 2008). In this study, only the green “deep” receiver signal (out of the 4 channels) was analyzed.

\section{ALB data processing}

LiDAR intensity is recorded as a function of time and the resulting waveform can be used to get information on the different environments crossed by the laser beam. The backscattered intensity waveform can be divided into three main parts: the water surface return, the water column, and the benthic (bottom) return (Fig. 2). The signal is delimited by 250 A.U. (relative photon count) and a duration of 185 nanoseconds.

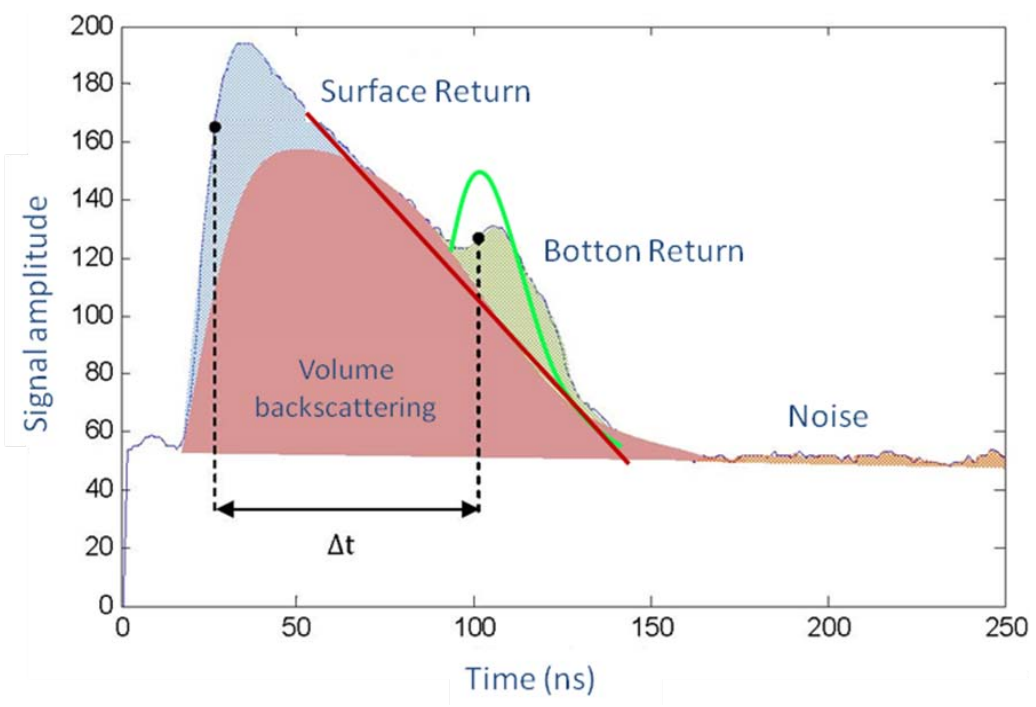

Figure 2. Example of a bathymetric LiDAR intensity waveform. The first peak corresponds to the water surface return and the second peak to the sea bottom (benthic) return. The solid line is a linear fit of the logarithmically amplified intensity return signal between water surface and sea bottom, and represents the laser intensity attenuation through water column.

In this study, only benthic returns were analyzed. This was achieved with the software IDL-ENVI which is recommended for its ability to deal with a large number of data and to build a rigorous protocol in order to compute accurate statistical parameters on specific portions of the waveform (Cottin 2008). Several regions of interest (ROIs) were chosen to reflect the diversity of bedforms and sedimentological facies at Paspebiac, and ALB data were extracted and converted into a DEM with a spatial resolution of $1 \times 1 \mathrm{~m}^{2}$. An IDL-ENVI protocol, based on Collin et al. (2008) protocol, was then used to identify the laser waveforms located within each ROIs, to isolate the benthic returns and to compute basic statistical parameters (mean, variance, skewness coefficient, kurtosis coefficient...). Erroneous data were corrected by using a nearest neighbor interpolation and depth attenuation was corrected by a non-linear bathymetric regression. 


\section{Laboratory experiment}

An open acrylic flume of $0.3 \times 0.3 \times 7 \mathrm{~m}$, looped by a pump of $1.51 \mathrm{~m}^{3} / \mathrm{min}$ capacity, was used to simulate the hydrodynamic field conditions (Fig. 3). The flume base was sand blasted, as recommended by Madsen and Durham (2007), and was consecutively filled with a $50 \mathrm{~mm}$ sand layer (Montreuil and Long 2007, 2009). The steady flow, measured by a Controlotron 1010 Doppler flow meter, was controlled by a PID regulator using a pneumatic valve installed in the pump looping circuit. The flume flow stability was measured at the average height velocity by a Vectrino tridimensional Doppler current meter (Gordon and Cox 2000). Medium sand $\left(\mathrm{d}_{50}=0.470 \mathrm{~mm}\right)$ and current velocity of $34 \mathrm{~cm} / \mathrm{s}$ were chosen, and CT-Scanner X-ray imagery and laser reflectance were acquired simultaneously over the current-generated sand ripples.

CT-Scanner imagery corresponds to a 2-D or 3-D linear X-ray attenuation pixel matrix where Xray attenuation is a function of the material's density, its effective atomic number, and the analyzed sample thickness. Consequently, CT-Scanner can be used to measure the relative density of materials such as sand layers in sedimentological studies (Duliu 1999, Ketcham and Carlson 2001, Duchesne et al. 2006, Mees et al. 2003). Relative density values vary from -1024 to +3071 Hounsfield units (HU) (Kak and Slaney 1999). Air and water values are respectively -1000 HU and $0 \mathrm{HU}$ (Ketcham and Carlson 2001). For the needs of this study, the relative HU density measurements were converted to $\mathrm{g} / \mathrm{cm}^{3}$. The equation used to convert and correct the beam-hardening and the Beer law effect of X-ray measurements is (ASTM 1992):

$$
\rho_{s}=-0.0257\left(\frac{H U+1024}{1000}\right)^{2}+1.0209\left(\frac{H U+1024}{1000}\right)-0.0254
$$

Where $\rho_{\mathrm{s}}$ is the density of the fluid-sediment mixture inside the flume and HU is the relative density measured with the CT-Scanner. The non invasive density measurements were acquired with a constant time interval $(\Delta \mathrm{t})$ of 30 seconds over a 100 minutes period, for a total acquisition time of 6000 seconds, in order to get a Lagrangian representation of sediment movement during the bedload transport process (Fig. 4). CT-Scanner data were combined to create a 4 dimensional matrix representing the sand evolution under fluid action during the 100 minutes time interval. The matrix was decomposed to isolate the bedload transport from the suspended transport using the position of the frontier density point (FDP) (Montreuil and Long 2007, 2009; Montreuil et al. 2008). A $3.5 \mathrm{~cm}$ wide section from the flume's central part was extracted from the resulting bedload transport matrix to avoid perturbations from the flume walls and to collect the data over the same area than the MAPLE laser system (see below). The ripple surface topography was expressed in function of the flume base.

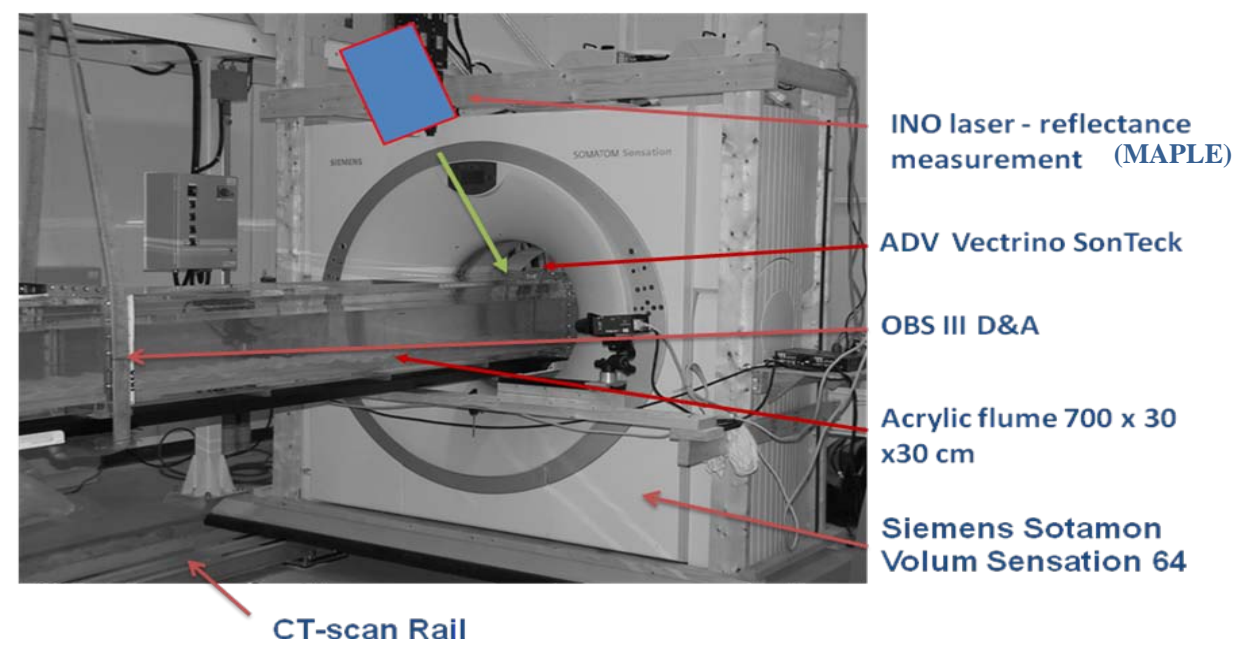

Figure 3. Experimental setup used to simulate current and bedform field conditions. 


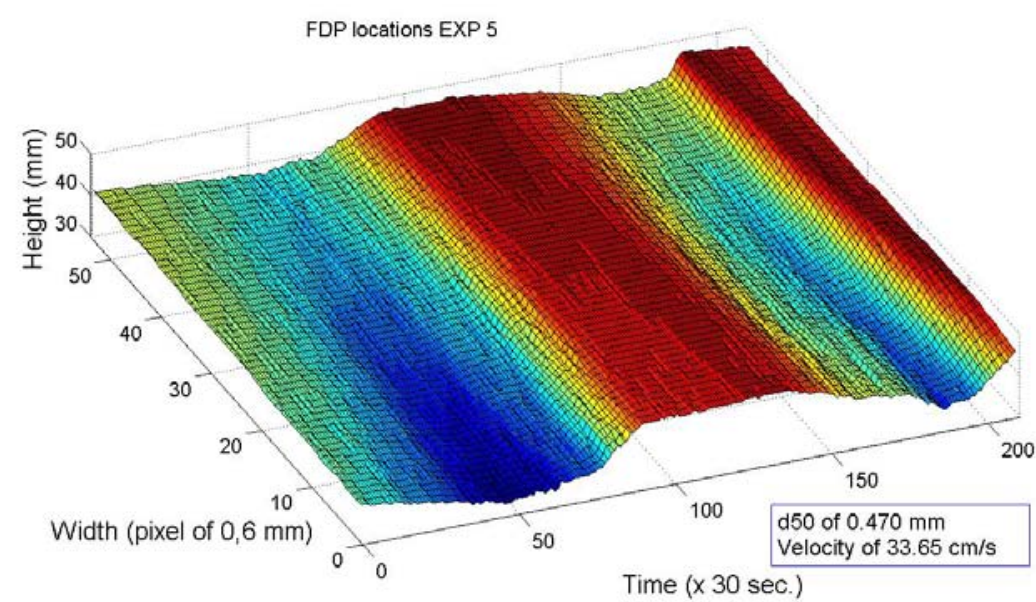

Figure 4. Example of sand ripple developed in the flume under a stationary current of $34 \mathrm{~cm} / \mathrm{s}$. The ripple MNT was generated with the CT-Scanner X-ray imagery. Crest height was $4.7 \mathrm{~cm}$ and the ripple morphology shifted from parallel to sinusoidal after $4500 \mathrm{~s}$. The width of the measured area was adjusted to be equal to the MAPLE laser footprint diameter $(3.5 \mathrm{~cm})$.

\section{CT-Scanner data analysis}

Montreuil et al. (2008) defined sedimentological parameters introducing specific separation points between sediment transport layers and the FDP, separating the suspension from the bedload transport (Fig. 5). The mass of sediment in the suspended transport zone (STZ) was computed by the integration of sediment mass in the volume, measured at time $\Delta \mathrm{t}$. In the present study, during the interval $(\Delta \mathrm{t})$, the sediment volume evolution was considered linear and the sediment velocity, equivalent to fluid velocity, was measured at the average height (z), of a log velocity profile by a Vectrino flow meter (Liu 2001). The resulting sediment transport rate was expressed in cubic centimeter per second per unit of width in centimeter.

Sediment concentration in the STZ was function of the CT-density measurement; the total bedload transport was function of the integrated density variations inside the mobile zone (function of the porosity variation). The upper bedload transport zone (UBTZ) was function of the viscosity, (Montreuil and Long 2009, Bridge and Demicco 2008). The total suspended load was calculated by the integration of suspended mass between the water surface and the FDP, including the viscous sublayer (Montreuil et al. 2009). The global mean porosity was obtained by the integration of the porosity measures between the FDP and the maximum density point (MDP).

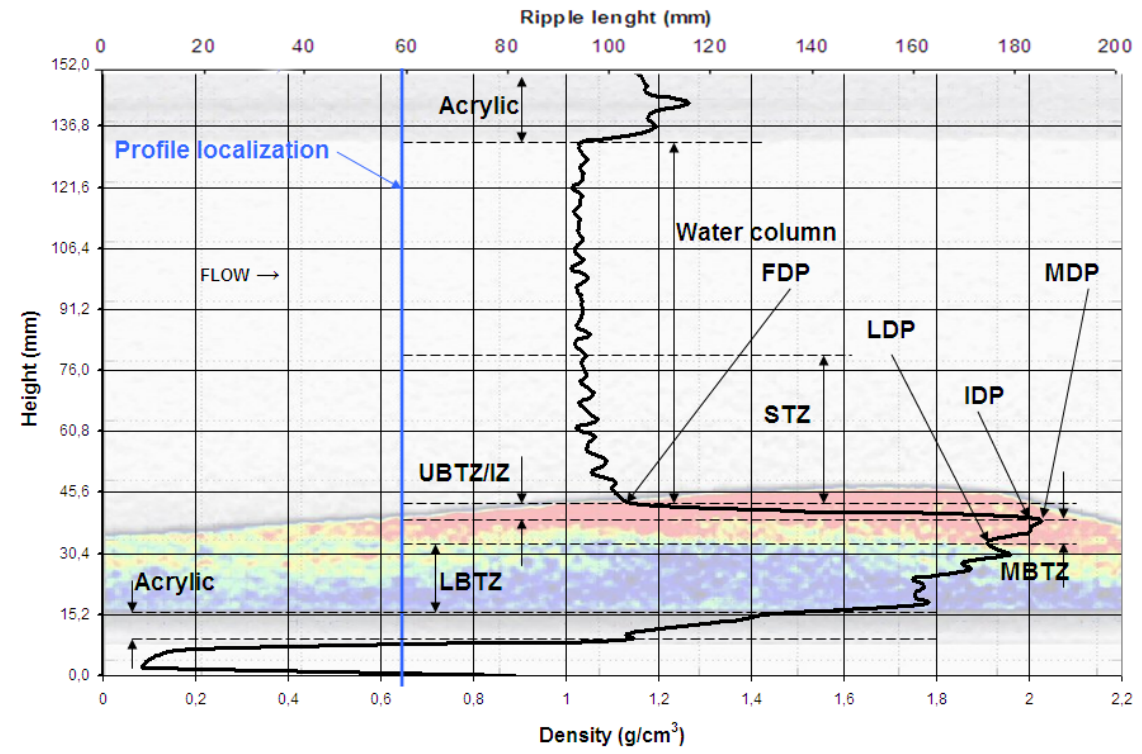

Figure 5. Example of vertical density variation, measured by X-ray tomography, within a bedform. The localization of the density profile on the ripple stoss-side is indicated by the blue solid line. The specific separation points between the different density layers defined by Montreuil et al. (2007) are shown. 


\section{Multi-beam autonomous portable laser (MAPLE) analysis}

The MAPLE system has been developed by the INRS in collaboration with INO (National Optic Institute) to help at the calibration of the ALB SHOALS system and relied on similar principles: an optoelectronic module emits two laser beams at $1064 \mathrm{~nm}$ (IR) and $532 \mathrm{~nm}$ (green-blue) wavelengths and a Campbell Scientific CR1000 datalogger records the backscattered energy for each wavelength as well as the respective incident laser energy, internal and external temperatures (as they affect the emitted laser energy), the range (source-target distance) and the laser beam incidence angle. The ratio between incident and backscattered laser energy provides information about the physical properties of the reflecting surface (Long and Robitaille 2009). In this study, the MAPLE system was positioned at a distance of $1.025 \mathrm{~m}$ from the flume base, with an incidence angle of $32.5^{\circ}$ in order to acquire laser reflectance measurements exactly at the same location, and at the same time, than the CT-Scanner Xray measurements. The water depth in the flume was $38 \mathrm{~cm}$ and the laser footprint diameter on the bottom was $3.5 \mathrm{~cm}$.

\section{RESULTS}

Results from the flume experiment are presented in Fig. 6 and 7. The MDP density values measured by CT-Scanner along the ripple bedform profile varied from $1.72 \mathrm{~g} / \mathrm{cm}^{3}$ on the lee-side to $1.99 \mathrm{~g} / \mathrm{cm}^{3}$ on the stoss-side (Fig. 6, bottom). The densities remained relatively low in the trough (55 to $80 \times 30 \mathrm{~s}$ ) with values ranging between 1.72 and $1.80 \mathrm{~g} / \mathrm{cm}^{3}$. They increased rapidly to $1.95 \mathrm{~g} / \mathrm{cm}^{3}$ on the lee-side of the ripple (80 to $95 \times 30 \mathrm{~s}$ ) and remained relatively constant on the crest with mean values of $1.95 \mathrm{~g} / \mathrm{cm}^{3}$. The peak MDP density values were observed around $120 \mathrm{x} 30$ seconds, at the two-third of the stoss-side of the bedform, with values ranging between 1.95 and $1.99 \mathrm{~g} / \mathrm{cm}^{3}$.

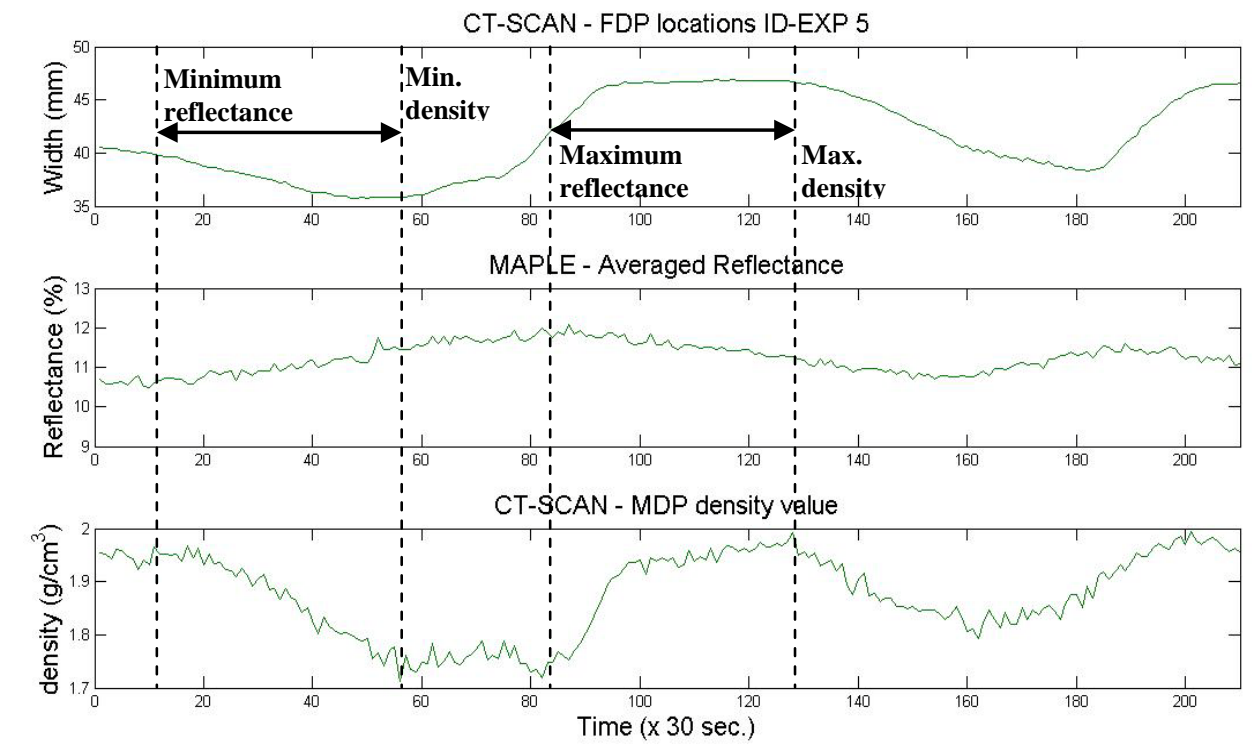

Figure 6. Lab experiment results: laser averaged reflectance measured by MAPLE laser (middle) and MDP density values measured by CT-Scanner X-ray imagery (bottom) along the bedform profile (top). The minimum and maximum reflectance values were measured about $45 \times 30 \mathrm{~s}$ before the minimum and peak MDP density values respectively.

The backscattered laser intensities, measured simultaneously by the MAPLE system along the ripple bedform profile, showed a slightly different trend (Fig. 6, middle). The averaged laser reflectance varied from $10.6 \%$ to $12.0 \%$ along the bedform profile but results indicate that the minimum and maximum reflectance values didn't coincide with the minimum and peak MDP density values. A shift of about 45 x 30s was observed between the maximum laser reflectance and the peak MDP density. The minimum MAPLE laser reflectance was measured at the two-third of the ripple stoss-side (between 0 and $20 \times$ 30s) with averaged values of $10.6 \%$. Reflectance values increased from $10.6 \%$ to $11.5 \%$ in the trough of the ripple and reached a maximum value of $12.0 \%$ on the lee-side of 
the bedform. Reflectance started to decrease on the crest and reached a new minimum of $10.6 \%$ on the next two-third of the stoss-side.

The frontier density point (FDP), which is defined as the suspended transport zone (STZ) lower limit and separates suspended sediment transport from bedload sediment transport, exhibited similar variations along the bedform profile (Fig. 7). Minimum FDP density values of $1.14 \mathrm{~g} / \mathrm{cm}^{3}$ were observed on the stoss-side of the ripple while peak FDP values, ranging between $1.25 \mathrm{~g} / \mathrm{cm}^{3}$ and 1.26 $\mathrm{g} / \mathrm{cm}^{3}$, were measured in the trough of the ripple. Intermediate density values of $1.23 \mathrm{~g} / \mathrm{cm}^{3}$ and 1.21 $\mathrm{g} / \mathrm{cm}^{3}$ were observed on the lee-side, decreasing from trough to crest. As FDP depends mainly on the amount of suspended sediment in the STZ, these results indicate that the suspended sediment concentration in the STZ was higher in the trough and on the lee-side of the ripple bedform than on the stoss-side.
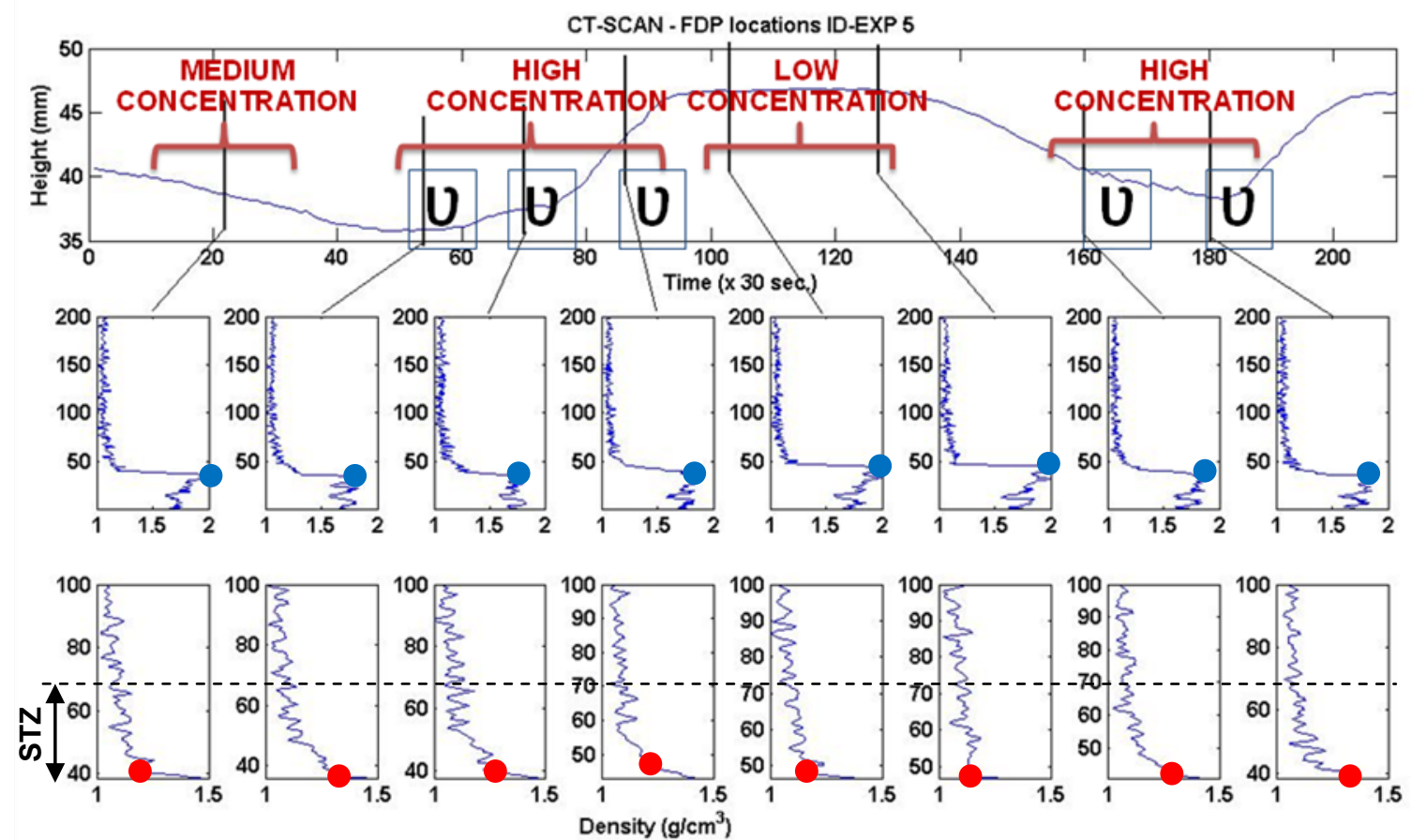

Figure 7. Vertical density distribution along the ripple bedform profile and location of MDP (upper graph), FDP and STZ (lower graph). The symbol $U$ indicates the presence of turbulent flow and vortices.

Field results are coherent with the lab observations and are presented in Fig. 8. Along a specific single subtidal bedform, located between $4 \mathrm{~m}$ and $6 \mathrm{~m}$ of water depth, the ALB benthic return laser intensities were found to range between 84 A.U. and 94.1 A.U (relative photon count unit). The minimum backscattered intensity value (84 A.U.) was measured at the two-third of the stoss-side of the bedform while the maximum backscattered intensity value (94.1 A.U.) was observed on the crest. Moreover, ALB intensity values were found to be higher in the trough (90.2 A.U.) than on the stossside where values decreased from 94.1 A.U on the crest to 87.1 A.U. on the first third of the stoss-side and 85.4 A.U. on the last third. This corresponds to an increase in reflectance of $6.8 \%$ in the trough, $10.7 \%$ on the crest, $5.0 \%$ on the first third of the stoss-side and $1.7 \%$ on the last third of the stossside, if compared to the minimal reflectance value of 84 A.U. measured along the bedform profile. 


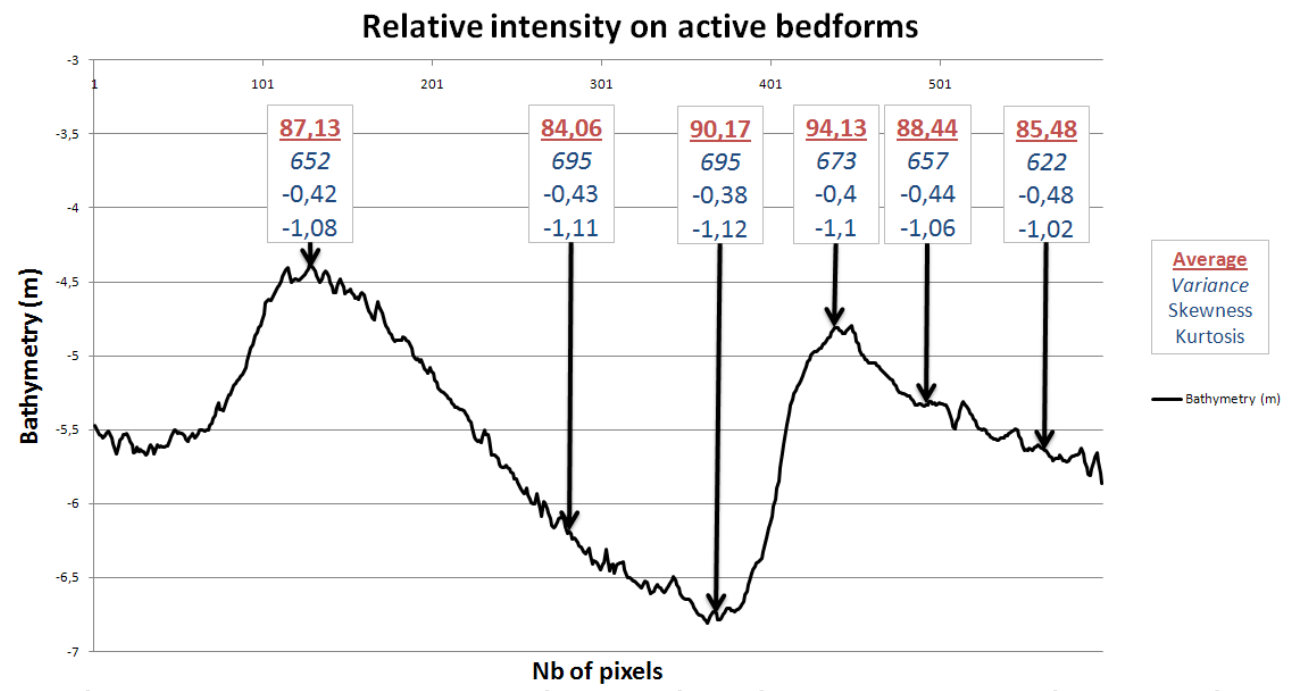

Figure 8. Field results: averaged ALB benthic return intensity values along subtidal hydraulic dunes at Paspebiac site, Canada. Depths refer to the mean sea level and are expressed in meters. Intensity values are expressed in relative photon count units (A.U.) and are corrected for the depth attenuation effect.

When several subtidal hydraulic dunes are studied, ALB intensity values exhibit a greater variability with values ranging between 84.3 A.U. and 102.6 A.U (Fig. 9 and 10). Nevertheless, maximum values were still observed near the crest of the bedform and minimum values near the trough. The two subtidal dunes located above $5 \mathrm{~m}$ depth (defined as "active bedforms" as they were located above the limit of wave action at this site) had maximum intensity values of 102.6 A.U. and 102.1 A.U., and minimum values of 89.8 A.U. and 96.3 A.U. respectively. This corresponds to an increase in reflectance of $14.3 \%$ and $5.7 \%$ respectively between trough and crest.

On the sand dunes located below the limit of wave action (and defined as "passive bedforms"), SHOALS intensity values were found to be smaller than on active bedforms. Maximum values of respectively 99.3 A.U., 96.1 A.U. and 92.4 A.U. were measured on the dune crests, and minimum values of 93.6 A.U., 89.1 A.U. and 84.3 A.U. were observed on the respective troughs. This corresponds to an increase in reflectance of $5.7 \%, 7.3 \%$ and $7.4 \%$ respectively between trough and crest of the bedforms.

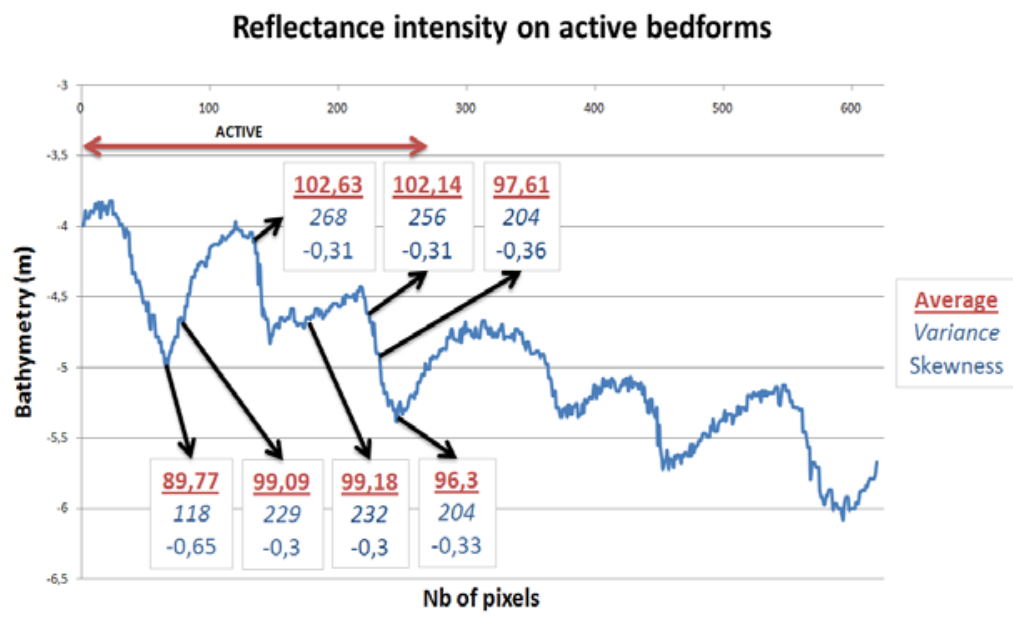

Figure 9. Field results: averaged ALB backscattered intensity, variance and skewness coefficient (benthic return) along shore-oblique "active" subtidal hydraulic dunes at Paspebiac site, Canada. Depths refer to the mean sea level and are expressed in meters. Intensity values are expressed in relative photon count units (A.U.) and are corrected for depth attenuation effect. 


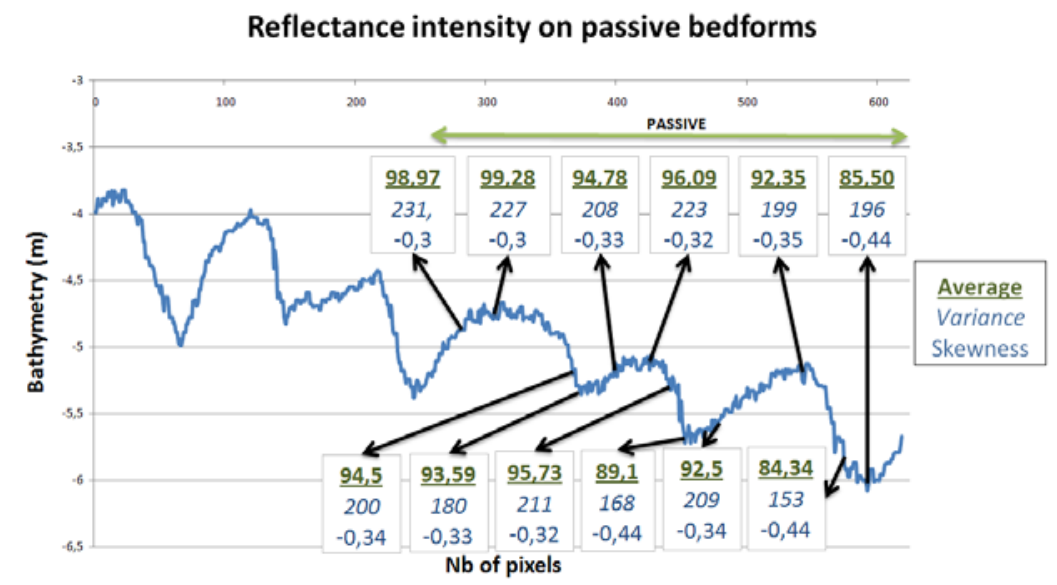

Figure 10. Field results: averaged ALB backscattered intensity, variance and skewness coefficient (benthic return) along shore-oblique "passive" subtidal hydraulic dunes at Paspebiac site, Canada. Depths refer to the mean sea level and are expressed in meters. Intensity values are expressed in relative photon count units (A.U.) and are corrected for depth attenuation effect.

\section{DISCUSSION}

MDP variation along the ripple bedform profile is in good agreement with previous results (Montreuil et al. 2008) which showed that variations in sediment transport profiles exist along the ripple stoss-side. Montreuil et al. (2008) demonstrated that the peak MDP was reached on the two-third of the stoss-side, as observed in the present study. The MDP variations along the ripple profile are correlated with the hydrodynamic pressure variation along the stoss-side surface (Raudkivi 1963, Vanoni and Hwang 1967, Middleton and Southard 1977). Indeed, the hydrodynamic pressure increases along the stoss-side and decreases dramatically on the lee-side, which result in a more dense (i.e. compact) sediment on the stoss-side than on the lee-side.

In the present study, laser reflectance results indicate that no direct relationship exists between backscattered laser intensity and MDP values (i.e. sediment density or compaction). Indeed, a shift between maximum laser reflectance and peak MDP value is observed, and the maximum laser reflectance is measured on the lee-side or on the crest of the ripple, where MDP values are lower. At the opposite, the minimum laser reflectance is observed at the two-third of the stoss-side or in the trough, where MDP values are the highest. Our results suggest instead the existence of an inverse relationship between laser reflectance and sediment compaction. Compact sediment forms a flatter and smoother surface than loose sediment, which affects laser beam reflection processes. When the sediment is compact (i.e. dense) and/or the laser beam incident angle is high, such as observed on the stoss-side of the ripples or on "passive" subtidal bedforms, an important part of the incident laser beam energy is reflected away of the sensor through specular reflection processes and small reflectance values are recorded. When the sediment is less compact and/or the incident laser beam angle is small, such as on the lee-side of the ripples or on "active" subtidal bedforms, a greater part of the incident laser beam energy is backscattered in the sensor direction through diffuse reflection processes (Rayleigh or Lambertian reflection) and higher reflectance values are observed. In future work, the effects of laser beam incidence angle and sea bed slope on the laser reflectance will be corrected in order to quantify more accurately the contribution of suspended sediment on the backscattered laser intensity (Aucoin, in prep.).

FDP and STZ measurements also indicate that turbulence and suspended sediment transport above the sand bed can contribute to the increase of laser reflectance observed on the lee-side of the ripple bedform. Indeed, FDP and STZ values are higher on this part of the bedform profile than on the stossside. Once again, this is due to the rapid drop in hydrodynamic pressure that occurred on the lee-side of the ripple, resulting in turbulent processes which increase the amount of sediment in suspension and decrease the compaction (i.e. MDP value) of the sand bed. Then the main bedload transport components, located in the upper bedload transport zone (UBTZ) correlates with reflection with is base on MDP (Montreuil et al., 2008). The exact location of the reflector within the UBTZ remains however unknown, but recent lab experiments reveal that the green laser can penetrate a pure quartz sand layer by $1.5 \mathrm{~mm}$ (Aucoin et al. in prep.). Laser reflection in the sand bed is thus expected to occur between FDP and $1.5 \mathrm{~mm}$ below FDP. 
Though suspended sediment increase the laser beam attenuation within the water column and decrease the amount of laser energy that reaches the seabed, this attenuation can be compensated by a greater amount of laser energy backscattered by the suspended sediment in the direction of the sensor through diffuse reflection and diffusion processes. The increase in laser reflectance was already highlighted by Long and Robitaille (2009). The authors showed that laser reflectance increases when suspended sediment concentration reached a threshold value which depends mainly on the sediment type and the laser wavelength. This threshold concentration was found to be $0.018 \mathrm{~g} / \mathrm{cm}^{3}$ for quartz sand and $532 \mathrm{~nm}$ wavelength (Long and Robitaille 2009) which is far below the suspended concentrations observed in the present study. As a consequence, the higher suspended sediment concentration on the lee-side of the ripple bedform is expected to contribute for a great part in the total backscattered laser energy and can explain the higher reflectance values observed on the lee-side of the bedform. However, the contribution of each process (suspended sediment and seabed backscattering) to the total backscattered reflectance has still to be determined.

\section{CONCLUSION}

In this study, the possibility to get sedimentological (porosity, compaction) and hydrodynamical (suspended sediment concentration, turbulence) information from ALB surveys was demonstrated. ALB return intensity waveforms were analyzed and correlated to bedform morphology and depth. ALB laser reflectance was found to be higher on the crest of subtidal hydraulic dunes than on the trough. Moreover, laser reflectance was also found to be higher on "active" subtidal dunes, located within the depth of action of the waves, than on deeper "passive" bedforms. Based on lab experiments conducted in a hydraulic flume under X-ray CT-Scanner, these observations were related to sediment compaction and suspended sediment.

Lab results indicate that sediment is less compact (dense), and suspended sediment transport is higher, on the lee-side of the ripple bedform due to the existence of turbulent hydrodynamic processes. In these conditions, laser reflectance is higher on the lee-side and near the crest of the bedform because a greater part of incident laser energy is reflected in the direction of the sensor by loose suspended and bed sediment through diffuse reflection processes. On the field, such "low compaction and high suspension" conditions are observed on subtidal "active" bedforms where sediment is reworked and put in suspension by wave action. At the opposite, lab results indicate that sediment is more compact (dense), and suspended sediment transport is lower, on the stoss-side of the bedform because of the absence of turbulent hydrodynamic processes. In these conditions, laser reflectance is found to be lower on the stoss-side and near the trough of the bedform because a greater part of incident laser energy is reflected away of the sensor through specular reflection processes. On the field, such "high compaction and low suspension" conditions are observed on subtidal "passive” bedforms where sediment is not reworked by wave action and suspended sediment concentration are thus lower.

\section{ACKNOWLEDGEMENTS}

This study was funded by the GEOIDE Network, with additional support from the Canadian Foundation for Innovation, the Geological Survey of Canada (Natural Resources Canada), the Department of Fisheries and Oceans (FPO) and the U.S. Navy. The SHOALS survey was performed by Dynamic Aviation with the support of the U.S. Navy and Optech International Inc. The authors are thankful to Antoine Collin for his precious support in ALB data processing and analysis. The authors would also thank Louis-Frédéric Daigle, Mathieu Desroches and Constant Pilote for their contribution in CT-Scanner and MAPLE data acquisition and analysis, Antoine Collin for the contribution in data reduction. Finally, we thank Mrs C. Roberge for internal review.

\section{REFERENCES}

Ashley, G.M., 1990. Classification of large-scale subaqueous bedforms: a new look at an old problem. Journal of Sedimentary Research, 60 (1), 161-172.

ASTM, 1992. Standard Guide for Computed Tomography (CT) Imaging, ASTM Designation E 1441 92a. In: 1992 Annual Book of ASTM Standards, Section 3 Metals Test Methods and Analytical Procedures. ASTM, Philadelphia, pp. 690-713.

Aucoin, F. Relation entre la densitométrie et les valeurs moyennes d'intensité relative du bleu-vert sur différentes figures sédimentaires en eau peu profonde. Québec: INRS-ETE, Ph.D. thesis, in prep. 
Aucoin, F., Long, B.F., Xhardé, R., 2011. Using airborne lidar bathymetry to map coastal hydrodynamic processes. Proceedings Coastal Sediments '11 Conference, ASCE, Miami, FL, in prep.

Baltsavias, E.P. 1999. A comparison between photogrammetry and laser scanning. ISPRS Journal of Photogrammetry \& Remote Sensing, 54, 83-94.

Bridge, J. and Demicco R., 2008. Earth Surface Processes, Landforms and Sediment Deposits. Cambridge University Press, New York, 830pp.

Brock, J.C., Wright, C.W., Sallenger, A.H., Krabill, W.B., and Swift, R.N., 2002. Basis and methods of NASA airborne topographic mapper Lidar surveys for coastal studies. Journal of Coastal Research, 18(1), 1-13.

Canadian Hydrographic Survey, 2006. Sailing Directions: Gulf of St. Lawrence (Southwest portion). Ed. Fisheries and Oceans Canada, 156 p.

Collin, A., Archambault, P., and Long, B.F., 2008. Mapping the shallow water seabed habitat with the SHOALS. IEEE Transactions on Geoscience and Remote Sensing, 46(10), 2947-2955.

Collin, A., Long, B.F., and Archambault, P., 2010. Salt-marsh characterization, zonation assessment and mapping through a dual-wavelength LiDAR. Remote Sensing of Environment, 114(3), 520530.

Cottin, A., 2008. Adaptation du SHOALS à la cartographie sédimentaire côtière peu profonde dans la Baie des Chaleurs, Québec, Canada. Québec: INRS-ETE, Ph.D. thesis, 259 p.

Cottin, A.G., Forbes, D.L., and Long, B.F., 2009. Shallow seabed mapping and classification using wave-form analysis and bathymetry from SHOALS LiDAR data. Canadian Journal of Remote Sensing, 35(5), 422-434.

Duchesne, M.J., Long, B.F., Labrie, J., and Simpkin, P.G., 2006. On the use of computerized tomography scan analysis to determine the genesis of very high resolution seismic reflection facies, J. Geophys. Res., 111, B10103, doi: 10.1029/2006JB004279.

Duliu, O.G., 1999. Computer axial tomography in geosciences: an overview. Earth-Science Reviews, 48, 265-281.

Gordon L. and Cox J., 2000. Acoustic Doppler Velocimeter Performance in a Laboratory Flume. Report for National Sedimentation Laboratory, Mississippi.

Guenther G.C., Cunningham, A.G., LaRocque, P.E., Reid, D.J., 2000. Meeting the Accuracy Challenge in Airborne LiDAR Bathymetry. EARSel proceedings, Dresden. 27 p.

Irish, J.L., McClung, J.K. and Lillycrop, W.J., 2000. Airborne lidar bathymetry: the SHOALS system. PIANC Bulletin, 2000(103), 43-53.

Kak A.C. and Slaney M., 1999. Principles of computerized tomographic imaging, IEEE PRESS, New York, 329 pp.

Ketcham R.A. and Carlson, W.D., 2001. Acquisition, optimization and interpretation of X-ray computed tomographic imagery: applications to the geosciences, Computers \& Geosciences 27, p. $381-400$.

Krabill, W.B., Thomas, R.H., Martin, C.F., Swift, R.N., and Frederick, E.B., 1995. Accuracy of airborne laser altimetry over the Greenland ice sheet. Int. J. Remote Sensing, 16, 1211-1222.

Liu Z, 2001. Sediment transport, Laboratoriet for Hydraulik og Havnebygning, Instituttet for Vand, Jord og Miljøteknik. Aalborg Universitet 71 p.

Long, B.F., and Robitaille, V., 2009. Use of a multi-beam autonomous portable laser equipment (MAPLE) to measure the reflectance of shallow water facies and habitats - a new tool to calibrate airborne laser bathymetry instruments. In: Proceedings of the $2^{\text {nd }}$ FUDOTERAM Workshop (Québec, Canada).

Madsen, O.S., Durham W.M., 2007. Pressure-Induced subsurface sediment transport in the surf zone. Proceedings Coastal Sediments '07 Conference, ASCE, New Orleans, LA, 1:82-95.

Mees, F. Swennen, R., Van Geet, M. and Jacobs, P., 2003. Applications of X-ray computed Tomography in the Geosciences. Geological Society of London Special Publication, 215.

Middleton, G.V., Southard, J.B., 1977. Mechanics of sediment movement, S.E.P.M. Short Course $\mathrm{n}^{\circ} 3$, Binghamton.

Montreuil, S., and Long, B.F., 2007. Flume Experiments under CAT-Scan to measure internal sedimentological parameters during sediment transport, Proceedings Coastal Sediments '07 Conference, ASCE, New Orleans, LA,1:124-136.

Montreuil S. and Long B., 2009, CT-Scanning: A new way to measure sediment transport inside a flume, Proceedings International Association of Hydraulic Engineering \& Research '09 
Conference, ASCE, Vancouver.

Montreuil, S., Long, B., and Kamphuis, J.W., 2008. Surface density variations along a sand ripple under stationary flow measured by CT-Scanning. Proceedings Coastal Engineering '08 Conference CERC and ASCE, Hamburg, Germany.

Pope, R.W., Reed, B.A., West, G.W., and Lillycrop, W.J., 1997. Use of an airborne laser depth sounding system in a complex shallow-water environment. Proceedings of the $15^{\text {th }}$ Hydrographic Symposium and International HydroConference (Monaco).

Raman, C.V., 1928. A New Radiation. Indian Journal of Physics, 2:387.

Raudkivi, A. J., 1963. Study of sediment ripple formation. Journal of the Hydraulic Division, ASCE, 89, $15-33$.

Renaud, L., 2000. Evolution et dégradation du barachois de Paspébiac. UQAR, M.Sc. thesis, 123 p.

Riley, J.L., 1995. Evaluating SHOALS bathymetry using NOAA hydrographic survey data. Proceedings of the $24^{\text {th }}$ Joint Meeting of UJNR Sea-Bottom Surveys Panel (Japan).

Sallenger Jr., A.H., Krabill, W., Swift, R., Brock, J., List, J.H., Hansen, M., Holman, R.A., Manizade, S., Sontag, J., Meredith, A., Morgan, K., Yunkel, J.K., Frederick, E.B., and Stockdon, H., 2003. Evaluation of airborne topographic Lidar for quantifying beach changes. Journal of Coastal Research, 19(1), 125-133.

Stockdon, H., Sallenger Jr., A.H., List, J.H., and Holman, R.A., 2002. Estimation of shoreline position and change using airborne topographic Lidar data. Journal of Coastal Research, 18(3), 502-513.

Vanoni, V. A. and Hwang, L. S., 1967. Relation between bedforms and friction in streams. Journal of the Hydraulics Division, ASCE, 93, HY3, pp. 121-144.

Woolard, J.W., Colby, D.J., 2002. Spatial characterization, resolution, and volumetric change of coastal dunes using airborne LIDAR: Cape Hatteras, North Carolina. Geomorphology, 48, 269287.

Xhardé, R., Long, B.F., and Forbes, D.L., 2010. Short-Term Beach and Shoreface Evolution on a Cuspate Foreland Observed with Airborne Topographic and Bathymetric LiDAR. Journal of Coastal Research, in press. 